\title{
Relationship between Time Interval from Admission to Delivery and Obstetrics Outcomes in Eclampsia/Severe Preeclampsia
}

\section{Pandit U}

Department of Obstetrics and Gynecology, Nepalgunj Medical College, Teaching Hospital, Nepalgunj, Nepal

Received: January 22, 2016 ; Accepted: March 25, 2016

\begin{abstract}
Aims: The purpose of this study was to find out the time interval from admission to delivery in eclamptic/ severe preeclamptic mothers and see the relationship to their obstetrics (maternal and fetal) outcomes.

Methods: A retrospective case review was conducted at Nepalgunj Medical College, Teaching hospital, Nepalgunj. About 152 mothers with eclampsia/severe preeclampsia and postpartum eclampsia whom received either loading or both loading and maintenance doses of Magnesium Sulfate, while they were admitted to the hospital from 1stJanuary 2011 to 31 st December 2015. Out of them, 132 were eclampsia/severe preeclampsia (antepartum / intrapartum) and 20 mothers were postpartum eclampsia were enrolled in the study. Descriptive analysis was used by reviewing medical records and Maternity registers. A $95 \%$ CI and P-value of $<0.05$ were considered as statistically significant.
\end{abstract}

Results: Among 132 mothers, 53 (40.1\%), 35 (26.5\%) and 44 (33.3\%) mothers delivered within 2 hours, 6 hours and $\geq 12$ hours respectively. Ninety seven (73.4\%) mothers underwent caesarean section, 27 (20.4\%) had spontaneous vertex delivery $8(6 \%)$ underwent assisted vaginal deliveries. Out of 139 births there were $118(84.8 \%)$ live births; 21 (15.1\%) still births. The apgar score $\geq 7$ at 5 minutes was seen in $81(58.2 \%)$ babies and low apgar $<7$ was seen in $37(26.6 \%)$ babies. and no evidence of live apgar "0" was seen in 23(16.5\%). There were 2 neonatal deaths. Eleven still births in 2 hours, 4 in 6 hours and 6 in $\geq 12$ hours of admission were noted .Among 152 mothers including postpartum 20(13.1\%) eclampsia, complications developed in $51(33.5 \%)$ mothers. Maternal deaths were $2(1.3 \%)$.

Conclusions: There is no significant difference in obstetrics outcomes in early ( 2 hour), later ( 6 hours) and late ( $\geq 12$ hours) delivery of eclamptic/severe preeclamptic mothers.

Keywords: admission to delivery time interval; eclampsia/severe preeclapsia; obstetrics outcome.

\section{INTRODUCTION}

Eclampsia and severe preeclampsia is accounted for 343000 (14\%) maternal deaths worldwide. ${ }^{1}$ Among them, $10 \%$ of deaths are from southern Asia. In Nepal, eclampsia is a leading cause of maternal mortality in health facilities (accounted for 30\%). ${ }^{2}$

About 18\% of maternal death occurs within four hours of admission, 39\% within 12 hours and 53\% within 24 hours respectively. ${ }^{3}$ This indicates that delays in the health facility is one of the proximal or immediate outcome determinants of maternal mortality. ${ }^{4}$ Eclampsia is also associated with a fivefold increase in perinatal mortality. ${ }^{5}$

Lack of drugs and equipments; trained manpower; policy and guidelines; infrastructure and delays

\section{CORRESPONDENCE}

Dr. Upendra Pandit

Assistant Professor

Nepalgunj Medical College, Teaching Hospital, Nepalgunj, Nepal

Phone: 977-1-9858032739

E-mail:drupandit@gmail.com in patient referral are identified as factors that add on the burden of maternal mortality. ${ }^{6}$ But, only a very few studies are available regarding timeliness interventions in obstetrics emergencies.

Eclampsia and severe preeclampsia are associated with various pregnancy related complications like postpartum hemorrhage, placental abruption, ${ }^{7-9}$ aspiration pneumonitis, HELLP syndrome, IUGR, intrauterine fetal death. The perinatal complications include still birth, premature delivery, low birth weight baby, neonatal intensive care unit admission, and birth asphyxia. ${ }^{13,14}$

The objectives of this study were to find out the time interval from admissions to delivery of eclamptic mother and to compare maternal and fetal outcome between three interval, early (within two hours), later (within six hours) and late ( $\geq 12$ hours) interval group with due respect to their mode of delivery.

\section{METHODS}

This is a descriptive study of retrospective data of eclamptic mother admitted and managed in maternity 
unit in Nepalgunj Medical College, Nepalgunj. It is a teaching hospital for Lord Buddha Educational Academy in western region of Nepal. It serves as a referral hospital in the Nepalgunj city. Obstetric case from remote districts of Nepal like Jumla, Humla, Kalikot, Rukum, Surkhet are referred in this hospital.

Secondary data were taken from primary data which were collected in maternity register and medical records. All mothers who had had antepartum and intrapartum eclampsia/severe preeclampsia and all eclamptic mothers who delivered at home and admitted in the hospital for the treatment of postpartum eclampsia were included in the study. A total 154 mothers with eclampsia/severe preeclampsia were admitted in four years time in hospital, among them 20 were postpartum eclampsia. Out of 154 mothers, 2 mothers whom had neurological cause of seizures or seizure disorders were referred to the higher centre and were excluded from the study. Out of 152 mothers, 132 mothers with antepartun and intrapartum eclampsia/ severe preeclampsia and 20 mothers with postpartum eclampsia were enrolled in the study. The admission to delivery time interval and obstetrics outcomes was seen among 132 mothers whom delivered at hospital. The maternal outcomes were seen among 152 mothers including mothers with postpartum eclampsia.

The variables include age, date and time of admission, address, gestational age, mode and time of delivery, Apgar score, birth weight, time interval between admission and delivery and maternal and fetal morbidity and mortality. Data were tabulated and analyzed using IBM SPSS statistics 20 version. A $95 \%$ confidence interval and p-value of $<0.05$ were considered as statistically significant. One-way ANOVA test within a group and between groups were compared to measures the significant level.

According to the local setting and available resources, the routine management protocol in Nepalgunj Medical College is as follows:

The patient is received by a duty nurse in the labor room, and is put in a comfortable position, her mouth and nose are cleaned if needed, oxygen 5 liter per minute is supplied via facemask, her vitals are recorded, IV line is opened (with 16-18 G cannula), blood is drawn for grouping and cross matching. Foley catheter is inserted into the urinary bladder. A bolus dose, $4 \mathrm{~g}$ of magnesium sulphate followed by $5 \mathrm{~g}$ of magnesium sulphate in each buttock is given initially, and $5 \mathrm{~g}$ of magnesium sulphate is given intra-muscularly four hourly in alternate buttocks. The duty nurse informs the consultant directly. Either the consultant attends the case or collects the finding from duty nurse. If diastolic blood pressure is more than $110 \mathrm{~mm}$ of $\mathrm{Hg}$ then Nefidepine (sublingual 10 $\mathrm{mg}$ every half an hour till it persist) is given. Baseline investigation includes hemoglobin, platelets count, serum creatinine level, blood sugar, urine for albumin and bilirubin, SGPT, serum uric acid, bleeding time (BT), clotting time (CT) are done as indicated. Respiration rate, urine output and tendon reflexes are monitored. As soon as patient is stable, the obstetrician decides the mode of delivery. Partograph is used in active stage of labour. Admission in intensive care unit is decided by the consultant.

\section{RESULTS}

A total 152 mothers were admitted and managed with eclampsia/severe preeclampsia. Among them $20(13.1 \%)$ were postpartum eclampsia. In the same period, 7605 deliveries were recorded. The hospital incidence of eclampsia/severe preeclampsia of 1.9 $\%$ ( 19.9/1000 deliveries) was identified. Almost all patients with seizures were treated with magnesium sulphate. Six (3.9\%) mothers had severe preeclampsia who received only loading doses of magnesium sulphate.

Most of the mothers were from Banke district (93), rest were from from Bardia (26), Kailali (13), Dang (9), Salyan (3), Surkhet (2), Pyuthan (2), Rolpa (2) and India (2). Among 132 mothers with antipartum/ intrapartum eclampsia, about 53 (40.1\%), 35 (26.5\%) and $44(33.3 \%)$ mothers delivered within 2 hours, 6 hours and $\geq 12$ hours, respectively. The mean time interval between admissions to delivery was $6.6 \pm 11.4$ hours. The range was 5 minutes to 96 hours. Figure 1 shows the time of admission in hours and time interval between admissions to delivery.

Figure 1 : Time interval between admissions to delivery in hours and No of deliveries.

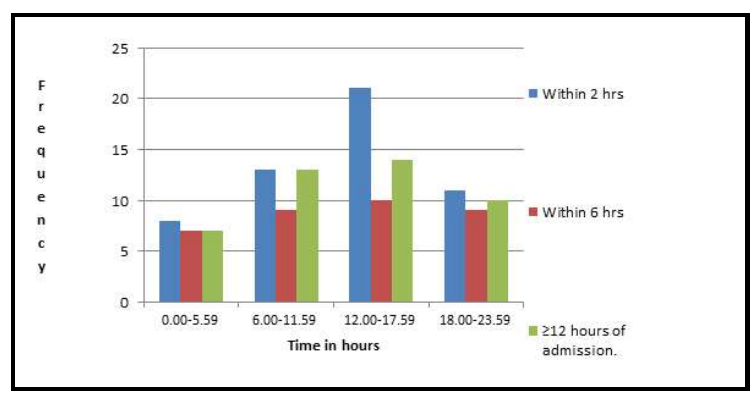


Table 1-4 shows the frequency distribution of variables related to the basic characteristics of mothers like maternal age, gravida, parity, and mode of delivery. Table 5-8 shows the frequency distribution of variables related to gestational age at delivery, Apgar score at 5 minutes and births and birth weight respectively. The mean age of mother was $21.8 \pm 4.6$. Forty one $(31.6 \%)$ cases were teenager, i.e., $<20$ years of age. Eleven $(8.3 \%)$ mothers were 30 or more years of age. The range of age was 14 to 42 years. Among 152 eclamptic/severe preclamptic mothers, 105 (79.5\%) were nulliparous, whereas only one mother had $>3$ parity. About $30 \%$ mothers had no check up for antenatal care. A significant differences was observed $(\mathrm{p}=0.02)$ in gravidity and nuliparity

Majority of the mothers $(97,73.4 \%$ ) underwent caesarean section followed by $27 \quad(20.4 \%)$ spontaneous vaginal deliveries and $8(6 \%)$ assisted vaginal deliveries. Almost all (20,13.1\%) postpartum eclamptic mothers delivered at home. The commonest gestational age was between 37-42 (46.2\%) weeks which was followed by $32-36(32.5 \%)$ and least observed was within 24-32 (11.3\%) weeks.

Tables 1 to 4 shows frequency distribution of basic characteristics of women with eclampsia/Severe preeclampsia and time interval between admissions to delivery.

Table: 1. Age Group Versus Time Interval from Admission to Delivery

\begin{tabular}{|ccccccc|}
\hline \multirow{2}{*}{ Age Group (n=132) } & \multicolumn{2}{c}{ Time Interval from Admission to delivery } & \multirow{2}{*}{ Total } & \multirow{2}{*}{ P } & P-value \\
& within 2 hours & within 6 hours & $\geq 12$ hours & & & \\
\hline $14-19$ & 20 & 9 & 12 & 41 & 31 & \\
$20-24$ & 26 & 16 & 23 & 65 & 49.2 & 0.1 \\
$25-29$ & 7 & 5 & 3 & 15 & 11.3 & \\
$>30$ & 0 & 5 & 6 & 11 & 8.3 & \\
Total & 53 & 35 & 44 & 132 & & \\
\hline
\end{tabular}

Table: 2. Gravida Versus Time Interval from Admission to delivery

\begin{tabular}{|c|c|c|c|c|c|c|c|}
\hline \multirow{2}{*}{\multicolumn{2}{|c|}{ Age Group $(n=132$}} & \multicolumn{3}{|c|}{ Time Interval from Admission to delivery } & \multirow{2}{*}{ Total } & \multirow{2}{*}{$\%$} & \multirow{2}{*}{ P-value } \\
\hline & & within 2 hours & within 6 hours & $\geq 12$ hours & & & \\
\hline & 1.00 & 48 & 25 & 32 & 105 & 79.5 & \\
\hline & 2.00 & 4 & 5 & 10 & 19 & 14.3 & 0.02 \\
\hline & 3.00 & 1 & 5 & 4 & 10 & 7.5 & \\
\hline & 4.00 & 0 & 0 & 1 & 1 & 0.7 & \\
\hline \multicolumn{2}{|l|}{ Total } & 53 & 35 & 44 & 132 & & \\
\hline
\end{tabular}

Table: 3. Parity Versus Time Interval from Admission to Delivery

\begin{tabular}{|clllllll|}
\hline \multirow{2}{*}{ Parity $(\mathrm{n}=132)$} & \multicolumn{2}{l}{ Time Interval from Admission to delivery } & \multirow{2}{*}{ Total } & $\%$ & P-value \\
\hline Nullipara & within 2 hours & within 6 hours & $\geq 1$ hours & & & \\
\hline 1.00 & 48 & 25 & 32 & 105 & 79.5 & 0.02 \\
2.00 & 5 & 8 & 7 & 20 & 15.1 & \\
Total & 0 & 2 & 5 & 7 & 5.3 & \\
\hline
\end{tabular}

Table: 4. Mode of delivery versus Time Interval from Admission to delivery

\begin{tabular}{|c|c|c|c|c|c|c|}
\hline \multirow{2}{*}{$\begin{array}{l}\text { Mode of Delivery } \\
(\mathrm{n}=130) \\
\text { within } 2 \text { hours }\end{array}$} & \multicolumn{6}{|c|}{ Time Interval from Admission to delivery } \\
\hline & within 6 hours & $\geq 12$ hours & & Total & $\%$ & P-value \\
\hline SVD* & 13 & 5 & 9 & 27 & 20.4 & \\
\hline AVD & 3 & 0 & 5 & 8 & 6 & 0.08 \\
\hline $\mathrm{CS}^{\dagger}$ & 37 & 30 & 30 & 97 & 73.4 & \\
\hline Total & 53 & 35 & 44 & 132 & & \\
\hline
\end{tabular}

$* \mathrm{SVD}=$ Spontaneous vertex delivery, $\uparrow \mathrm{CS}=$ Caesarean Section, $₫$ Assisted vaginal delivery (Forceps/Vaccum) 
The Tables 5- 8, shows frequency distributions of obstetric outcome of women with eclampsia/Severe preeclapsia whom delivered in hospital.

Table: 5. Gestational Age Verus Time Interval from Admission to Delivery

\begin{tabular}{|c|c|c|c|c|c|c|}
\hline \multirow{2}{*}{ Gestational Age $(\mathrm{n}=119)$} & \multicolumn{3}{|c|}{ Time Interval from Admission to delivery } & \multirow{2}{*}{ Total } & \multirow{2}{*}{$\%$} & \multirow{2}{*}{ P-value } \\
\hline & within 2 hours & within 6 hours & $\geq 12$ hours & & & \\
\hline $24-32$ & 7 & 4 & 4 & 15 & 11.3 & \\
\hline $32-36$ & 12 & 14 & 17 & 43 & 32.5 & 0.3 \\
\hline $37-42$ & 31 & 14 & 16 & 61 & 46.2 & \\
\hline unknown & 3 & 3 & 7 & 13 & 9.8 & \\
\hline Total & 53 & 35 & 44 & 132 & & \\
\hline
\end{tabular}

Table: 6. Apgar Score Versus Time Interval from Admission to Delivery

\begin{tabular}{|llllllll|}
\hline $\begin{array}{l}\text { APGAR (Group) } \\
\text { within } 2 \text { hours }\end{array}$ & $(\mathrm{n}=136)$ & \multicolumn{2}{l}{ Time Interval from Admission to delivery } & Total & $\%$ & P-value \\
\hline & within 6 hours & $\geq$ 12hours & & & \\
\hline & $1-3$ & 14 & 4 & 5 & 23 & 16.5 & \\
& $4-6$ & 1 & 1 & 1 & 3 & 2.1 & 0.07 \\
& $\geq 7$ & 13 & 9 & 11 & 33 & 23.7 & \\
Total & 27 & 23 & 30 & 80 & 57.5 \\
\hline
\end{tabular}

Table:7. Births Versus Time Interval from Admission to Delivery

\begin{tabular}{|llllllll|}
\hline Births & & \multicolumn{2}{l}{ Time Interval from Admission to delivery } & Total & $\%$ & P-value \\
& within 2 hours & within 6 hours & $\geq 12$ hours & & & \\
& Macerated & 4 & 2 & 0 & 6 & 4.3 & 0.07 \\
& Fresh & 8 & 2 & 5 & 15 & 10.7 & \\
& Live & 43 & 33 & 42 & 118 & 84.8 & \\
Total & & 55 & 37 & 47 & 139 & \\
\hline
\end{tabular}

Table:8. Birth Weight Versus Time Interval from Admission to Delivery

\begin{tabular}{|c|c|c|c|c|c|c|}
\hline \multirow{2}{*}{ Birth weight in Gram } & \multicolumn{3}{|c|}{ Time Interval from Admission to delivery } & \multirow{2}{*}{ Total } & \multirow{2}{*}{$\%$} & \multirow{2}{*}{ P-value } \\
\hline & within 2 hours & within 6 hours & $\geq 12$ hours & & & \\
\hline $500-1499$ & 3 & 3 & 4 & 10 & \multirow{4}{*}{$\begin{array}{l}7.1 \\
37.4 \\
58.3\end{array}$} & \multirow{4}{*}{0.2} \\
\hline $1500-2499$ & 22 & 16 & 14 & 52 & & \\
\hline$\geq 2500$ & 30 & 18 & 29 & 77 & & \\
\hline Total & 55 & 37 & 47 & 139 & & \\
\hline
\end{tabular}

Table: 8. Frequency Distribution of Maternal Outcome

\begin{tabular}{|lll|}
\hline Maternal Complications & $\mathrm{n}=152$ & \\
\hline PPH whom needed blood transfusion & Frequency. & $\%$ \\
Pulmonary Oedema / Respiratory failure & 19 & 12.5 \\
Aspiration pneumonitis & 4 & 2.6 \\
Acute renal failure & 12 & 7.8 \\
HELLP§ syndrome & 4 & 2.6 \\
Wound infection & 1 & 0.6 \\
Death & 9 & 5.9 \\
Total & 2 & 1.3 \\
\hline
\end{tabular}

§HELLP (Haemolysis, elevated liver enzyme and low platelets)

Majority of births were preterm. The mean gestational age at delivery was $35.8 \pm 3.7$. The preterm gestational age $(<37$ weeks) at delivery was observed in $58(43.9 \%)$ mothers. The association with preterm delivery and caesarean section was observed only in 40 (41.3\%) mothers. 
There were 139 births from 132 mothers. Seven mothers delivered twin births. Out of 139 births, 118 $(84.8 \%)$ were live, $15(10.7 \%)$ were fresh stillbirths and $6(4.3 \%)$ were macerated stillbirths. The Apgar score $\geq 7$ at 5 minutes was seen in $81(58.2 \%)$ babies and low Apgar $(<7)$ was seen in $37(26.6 \%)$ babies. Very low apgar $(<4)$ score was seen in $3(2.1 \%)$. No evidence of live Apgar " 0 " was seen in 21(15.1\%). There were 2 neonatal deaths. The perinatal death rate was observed 194 per 1000 live births.

Out of 152 mothers including postpartum eclampsia, $51(33.5 \%)$ mother developed complications during their treatment course of eclampsia and severe preeclampsia (Table -9). Postpartum haemorrhage was the leading complication $(19,12.5 \%)$ observed in eclamptic mothers. No case fatality was observed from postpartum haemorrhage. The second leading complication was aspiration pneumonitis observed in $12(7.8 \%)$ cases followed by surgical wound infection $(9,5.9 \%)$, pulmonary oedema/respiratory failure $(4,2.6 \%)$, and acute renal failure $(4,2.6 \%)$. HELLP syndrome was seen in one $(0.6 \%)$ mother and deaths in two (1.3\%). Case fatality was observed in 2 mothers, who died of acute renal failure and aspiration pneumonitis. The maternal mortality ratio in eclampsia is calculated as 1694.9 per 100000 live births.

\section{DISCUSSION}

This retrospective study demonstrated the hospital incidence of eclampsia/severe preeclampsia of $1.9 \%$. It is lower than incidence (2.9\%)reported at the Maternity Hospital, Kathmandu in 2003. ${ }^{9}$ Incidence is higher, compared to the findings at National Hospital Timor- Leste (1.2\%) and three different teaching hospitals in the south regional state of Ehiopia. ${ }^{10}$ The rate of postpartum eclampsia is lower in this series (13.1\%) compared to reporting rate $(29 \% ; 31.4 \%)$ in respective studies. ${ }^{10,11}$ However, the access and availability of prenatal care, combined with early recognition and effective management without delay has decreased the incidence of antepartum and early post partum eclampsia.

The three delays (Delay in the decision making, Delay in the distances and Delay in Destination of the institution) affect the maternal and perinatal outcomes. ${ }^{3}$ But, the delay in the institution, not only, due to well known factors (such as, drugs and equipments; trained manpower; policy and guidelines; infrastructure and patient and referral) but also, the motivation for appropriate timeliness interventions is the foremost important factor. An appropriate timeliness intervention reflects the outcome. So, this study highlighted the time interval between admission to delivery in eclamptic mothers that can determine the delay in terms of maternal and fetal outcome measures in different time interval. The median time interval between admissions to delivery was 6.67 hours. The range was 5 minutes to 96 hours. Significant difference was not observed in admission to delivery time in three intervals. About $65.1 \%$ mother delivered within 6 hours. Similar findings were reported in Benin, Ecuador, and Jamaica (2007). ${ }^{12}$ The two third majorities of the cases delivered within 6 hours show the active and prompt action. It strongly reflects the appropriate timeliness intervention. However, among operated mothers, within 6 hours of admission $26(18.7 \%)$ babies had given birth with low Apgar ( $<7$ score in 5 minutes). Babies who had low Apgar at birth were delivered by mothers referred from other than Banke districts, which indicates delay due to distance.

In this series, about $31 \%$ mothers were teenager $(<20$ years of age). The rate of teenage pregnancy is also high. Significant association was observed in primary gravid and nullipara $(\mathrm{p}=0.02)$. Large number of studies support this association. ${ }^{9}$ Eclampsia is associated with an increased rate of caesarean section. A number of studies show high caesarean section rate in eclampsia $(61 \%, 55.3 \%)$ in respective studies. ${ }^{9}, 13$ In this series, $73.4 \%$ of eclamptic mother underwent caesarean section as a mode of delivery. This finding is coherent with the reporting. ${ }^{13}$ The increasing rate of caesarean adds extra risk in next pregnancy. Home delivery was also observed (13.1\%) in postpartum eclampsia. All mothers with postpartum eclampsia delivered at home.

The commonest gestational age was between 37-42 (46.2\%) weeks, and followed by 32-36(32.5\%) and least observed was within 24-32 (11.3\%) weeks. Preterm gestational age ( $<37$ weeks at delivery) observed was $43.9 \%$ in this series. The association of caesarean section and preterm gestational age at delivery was observed in $40(41.2 \%)$ cases. No significant association was observed among groups of different time interval.

Apgar score 0 (no evidence of life) at 5 minutes was observed in $15.1 \%$ of cases. Still birth rate was 
calculated as $203 / 1000$ live births. It is very high compared to the finding in retrospective data of general obstetrics in Timor-Leste. ${ }^{14}$ Almost $15.1 \%$ of case were still born. Majority (57.1\%) were born within first 2 hours of admissions. About $76 \%$ still born were within 6 hours of admissions. 3 macerated still born from postpartum eclamptic mothers who delivered on the way to hospital was observed. No difference was observed between groups and time interval between admissions to delivery. The perinatal mortality ratio in eclampsia was observed in this series 194/1000 live birth. This is little lower rate compared to the reporting at one of the hospital in Nigeria in $2012^{15}$ but very high ratio, as compared to, the reporting 33.3/1000 in Kuwait. ${ }^{16}$. This shows poor antenatal coverage for early detection and management of preeclampsia.

Among 154 mothers, 51 (33.1\%) mother developed complications during their treatment course of eclampsia and preeclampsia. This complication rate is lower compared to the recent retrospective study in severe preeclampsia done in Finland. ${ }^{17}$ Postpartum haemorrhage was the leading complication (19,12.3\%) observed in eclamptic mother. Out of 20 postpartum eclamptic mother who delivered at home, $10(50 \%)$ needed blood transfusion. No case fatality was observed from postpartum haemorrhage. The second leading complication was aspiration pneumonitis $(12,7.7 \%)$ followed by surgical wound infection $(9,5.8 \%)$, puerperal pyrexia/urinary infection (8, $5.1 \%)$, and acute renal failure $(2,1.2 \%)$ The infection rate is high because of emergency caesarean section compared to general rate. Case fatality was observed in two mothers, who died of acute renal failure and aspiration pneumonitis. The maternal mortality ratio due to eclampsia was 1695 per 100000 live births. Perinatal mortality and maternal mortality ratio in eclamptic mother is estimated to be $>7$ times higher compared to the ratio in general population. A close monitoring as well as an attentive care is necessary during the course of management of eclamptic mother to minimize their morbidity and mortality.

This study has got some limitations. The data were from a single institution, so it represents a very small population. About $40 \%$ of cases were referred from districts other than Banke. The pre-convulsive status which affects the outcome of the eclamptic mother was unknown.

\section{CONCLUSIONS}

There is no significant difference in fetal outcomes in early (within two hours), later (within six hours) and late ( $\geq 12$ hours) delivery of eclamptic mothers. The mean delivery time observed was within 6.6 hours of admissions. This may be the ideal or optimal time interval for their delivery so that high rate of maternal and fetal complications can be avoided.

\section{ACKNOWLEDGEMENT}

I would like to thank Dr. Farhat Banu, Dr Kamar Jaha, Ms. Lila Aryal and all nursing staff for their continuous support and dedication in providing care and management of mother who suffered from eclampsia. I would like to acknowledge Dr. M. Kidwai, Hospital Director, Teaching Hospital, Nepalgunj, for his constant support and encouragement. I would also thank Dr. Asmita Sharma and Dr. Baidehi Upadhyaya for their help in the study.

\section{REFERENCES}

1. Say L, Chou D, Gemmill A, Tuncalp O, Moller AB, Daniels $\mathrm{J}$ et al. Global causes of maternal death: a WHO systematic analysis. Lancet Glob Health. 2014;2: e323-33.

2. Ministry of Health and population (MoHP) [Nepal].Annual Report of the Department of Health Services Kathmandu, Government of Nepal; 2014.

3. Suvedi BK, Pradhan A, Barnett S, Puri M, Chitrakar SR, Poudel P et al. Nepal Maternal Mortality and Morbidity Study 2008/2009: Summary of Preliminary Findings. Kathmandu, Nepal.Ministry of Health, Government of Nepal. 2010.

4. Onah HE, Okaro JM, Umeh U, Chigbu CO. Maternal mortality in health institutions with emergency obstetric care facilities in Enugu State, Nigeria. J Obstet Gynaecol. 2005;25: 569-74.

5. Osoro AA, Ng'ang' Z, Mutugi M, Wanzala P. Determinants of maternal mortality among women of reproductive age attending Kissi General Hospital, Kissi
Central District, Kenya (January 2009-June 2010). East Afr Med J. 2013; 90: 253-61.

6. Knight HE, Self A, Kennedy SH. Why are women dying when they reach hospital on time? A systematic review of the 'Third Delay'. PLoS One. 2013; 8: e63846.

7. Nakimuli A, Mbalinda SN, Nabirye RC, Kakaire O, Nakubulwa S, Osinde MO et al. Still births, neonatal deaths and neonatal near miss cases attributable to severe obstetric complications: a prospective cohort study in two referral hospitals in Uganda. BMC Pediatr. 2015;15:44

8. Allanson ER, Muller M, Pattinson RC. Causes of perinatal mortality and associated maternal complications in a South African province: challenges in predicting poor outcomes. BMC Pregnancy Childbirth. 2015;15: 37.

9. Choudhary P. Eclampsia: a hospital based retrospective study. Katmandu Univ Med J. 2003;1: 237-41. 
10. Berhan Y, Endeshaw G. Clinical and biomarkers differences in prepartum and postpartum eclampsia. Ethiop J Health Sci. 2015;25: 257-66.

11. Sharara HA. A review of eclampsia in Qatar: a twenty-year study (from January 1991-December 2009).Qatar Med J. 2013;2012: 7-15.

12. Edson W, Burkhalter B, McCaw-Binns A. Timeliness of care for eclampsia and pre-eclampsia in Benin, Ecuador, and Jamaica. Int J Gynaecol Obstet. 2007;97: 209-14.

13. Kidanto HL, Mogren I, Massawe SN, Lindmark G, Nystrom L. Criteria-based audit on management of eclampsia patients at a tertiary hospital in Dar es Salaam, Tanzania. BMC Pregnancy Childbirth. 2009;9:13.
14. Wilkins A, Earnest J, Mccarthy EA, Shub A. A retrospective review of stillbirths at the national hospital in Timor-Leste. Aust N Z J Obstet Gynaecol. 2015;55: 331-6.

15. Jido TA. Eclampsia: maternal and fetal outcome. Afr Health Sci. 2012;12:148-52.

16. Chibber R, Al-Hijji J, Amen A, Fouda M, Kaleemullah ZM, El-Saleh E et al. Maternal and perinatal outcome of eclampsia over a decade at a tertiary hospital in Kuwait. J Matern Fetal Neonatal Med. 2015;29: 3132-7.

17. Jaatinen N, Ekholm E. Eclampsia in Finland; 2006 to2010. Acta Obstet Gynecol Scand.2016;95: 787-92. 